\title{
Association between exercise-induced asthma and parental socio-economic status among school-aged adolescents in a semiurban community in Nigeria
}

\author{
Adekola A. Adewumi ${ }^{1,2}$, Rufus A. Adedoyin ${ }^{2}$, Taofeek 0. Awotidebe ${ }^{2, *}$, Gregory E. Erhabor ${ }^{3,4}$, Olayemi F. Awopeju ${ }^{3,4}$, Rita N. Ativie ${ }^{5}$, \\ Kayode I. Oke \\ 'Department of Physiotherapy, Federal Teaching Hospital, Ido-Ekiti, Ekiti State, Nigeria \\ ${ }^{2}$ Department of Medical Rehabilitation, College of Health Sciences, Obafemi Awolowo University, Ile-Ife, Nigeria \\ ${ }^{3}$ Chest Unit, Obafemi Awolowo University Teaching Hospitals Complex, Ile-Ife, Nigeria \\ ${ }^{4}$ Department of Medicine, College of Health Sciences, Obafemi Awolowo University, Ile-lfe, Nigeria \\ ${ }^{5}$ Department of Medical Rehabilitation, Faculty of Health Sciences and Technology, University of Nigeria, Enugu Campus, Enugu, Nigeria \\ ${ }^{6}$ Department of Physiotherapy, School of Medical Sciences, University of Benin, Benin City, Nigeria
}

This study investigated the prevalence and association between exercise-induced asthma (EIA) and parental socio-economic status (PSES) among school-aged adolescents in a semiurban community in Nigeria. Three hundred and eighty-five adolescents (185 male and 200 female adolescents) whose ages ranged between 10 and 19 years participated in this cross-sectional study. Participants were recruited from four government approved secondary schools in Ido-Ekiti using a multistage sampling technique. Peak expiratory flow rate (PEFR) was assessed at baseline and after 6-min run test (6-MRT) on a level playing ground using a standard peak flow meter. PEFR measurements were repeated at 5th, 10th, 15th, and 20th min post 6-MRT. Participants who had $>15.0 \%$ PEFR fall were considered to have EIA. PSES was assessed using a validated socio-economic status questionnaire. Descriptive and inferential statistics were used to analyze data. Alpha level was set at
$P<0.05$. The mean ages of males and females were $13.9 \pm 2.0$ and $13.8 \pm 1.6$ years, respectively. More than half of the participants, $58.2 \%$ had EIA ( $>15.0 \%$ PEFR scores) while $53.5 \%$ belonged to middle PSES class. There was no significant difference between PEFR scores of male and female participants at baseline and 5th min post 6-MRT. However, male participants had significant higher PEFR than the female counterparts at 10th $(t=2.090, P=0.037)$, 15th $(t=2.162, P=0.031)$, and 20th $\min (t=2.978, P=0.003)$. There was significant association between EIA and PSES $\left(\chi^{2}=152.4 ; P=0.001\right)$. The prevalence of EIA is very high among school-aged adolescents in Nigeria and was significantly associated with PSES.

Keywords: Exercise-induced asthma, Parental socio-economic status, School-aged adolescent, Southwest Nigeria

\section{INTRODUCTION}

Asthma is a chronic inflammatory respiratory tract disease that affects individuals of all ages which could be severe and even fatal (Cukic et al., 2012). Currently, more than 300 million people are suffering from asthma globally and its prevalence among children is on the increase (Adeloye et al., 2013; Shimwela et al., 2014). The prevalence of asthma has also been reported to be on the in- crease over the past few decades with the highest increase among children and adolescents living in the inner cities and regions where low prevalence had previously been reported (Crain et al., 1994; Matsui, 2014).

The prevalence of asthma is on the increase in both developed and developing countries over the last three decades (Okada et al., 2010; Onazi et al., 2012). For instance, the phase one report of the International Study of Asthma and Allergies in Children

\footnotetext{
${ }^{*}$ Corresponding author: Taofeek O. Awotidebe (iD http://orcid.org/0000-0002-8583-9467 Department of Medical Rehabilitation, College of Health Sciences, Obafemi Awolowo University, Ile-Ife, Nigeria

Tel: +234-80-3719-6021, Fax: +234-81-2612-6284

E-mail: tidebet@yahoo.com/ tawotidebe@cartafrica.org

Received: January 16, 2017 / Accepted: June 5, 2017
} 
(ISAAC, 1998) reported that the prevalence of asthma symptoms ranged from less than $5 \%$ in developing countries to more than $20 \%$ in developed countries (Shimwela et al., 2014). This increase has mainly been attributed to the increasing urbanization in developing countries including Africa (Akanbi et al., 2009). Nonetheless, the burden of respiratory disease still remains largely unknown in Africa.

Asthma is characterized by recurring symptoms of coughing, wheezing, difficulty in breathing, reversible airflow obstruction and bronchospasm (Erhabor et al., 2006). Because many respiratory conditions mimic asthma symptoms in children and adults, standardized research instruments such as ISAAC questionnaire and the European Community Respiratory Health Survey have been developed to gain better insight into the prevalence of asthma and other allergic diseases respectively (Janson et al., 2001). It is believed that good understanding of disease progression and its prevalence may help to prevent disease proliferation and develop an effective strategy for controlling it. Furthermore, there is growing advocacy among many health authorities to include regular participation in physical exercise as a strategy for curtailing the scourge of many chronic diseases including respiratory diseases such as asthma (USDHHS, 2008; World Health Organization, 2010).

Studies have shown that physical exercise is beneficial for improving endurance capacity and breathing work efficiency among apparently healthy individuals and improving health-related quality of life, reducing disability in people with respiratory challenges independent of disease severity (Lan et al., 2011). Therefore, exercise has been recommended as an integral part of management for patients with chronic obstructive pulmonary disease (COPD) including asthma (Ries et al., 2007). However, exercise as a form of health behaviour could be hamstrung by a number of factors including personal, disease progression and lack of self-efficacy (Awotidebe et al., 2016). More importantly, participation in regular exercise among adolescents may also be hindered by parental economic situation.

Socio-economic status (SES) is a complex concept that has been associated with many chronic diseases. There is growing evidence that parental SES (PSES) is associated with aetiological development of asthma in children (Mohammed et al., 2012). Although respiratory conditions in childhood may not actually result into asthma, presence of underlying respiratory pathology may trigger narrowing of the airways in individuals with unsuspected asthmatic condition during exercise programme. Thus, leading to exercise-induced asthma (EIA) despite no previous history of asthma related conditions (Anderson and Holzer, 2000). Similarly, pres- ence of EIA may limit regular participation in exercise programme for healthy living among adolescents. Unfortunately, there is dearth of information on the prevalence of EIA among adolescents. Furthermore, the association between EIA and parental SES has not been objectively explored among adolescents in Nigeria. The outcome of this study may be used to increase awareness on EIA and develop strategy for prevention of future asthmatic condition. Therefore, the objective of this study was to assess the prevalence of EIA and its association with parental SES of schoolaged adolescents in Ido-Ekiti, Ekiti State, Southwest, Nigeria.

\section{MATERIALS AND METHODS}

\section{Participants and location}

Participants for this study were school-aged adolescents attending approved government secondary schools in Ido-Ekiti, Ekiti State, Southwest, Nigeria. Ido-Ekiti is the headquarters of Ido/Osi Local Government Area (LGA) which is situated in the northern part of the state and comprises of other towns and rural communities such as Aaye, Ayetoro, Ido, Ifaki, Ilogbo, Igbole, Ora, Orin and Usi. The local government is bounded in the east by Ipere and Iludun, in the south by Igbole and Ifinsin axis and in the north and northwest by Usi and Ilogbo Ekiti. Ido-Ekiti is one of the fastest growing towns in Ekiti State and many people were attracted to the town due to the presence of a Federal Teaching Hospital formerly known as Federal Medical Centre, School of Nursing and many financial institutions. Recently, the teaching hospital has been affiliated with a private university; Afe Babalola University, Ado-Ekiti for the training of undergraduate medical students and as well as postgraduate medical fellowship in different specialties (Government of Ekiti State, Nigeria, 2015).

Participants for this study were selected using a multi-stage sampling method. Firstly, Ido/Osi LGA was purposively selected and secondly, four out of seven government approved secondary schools were randomly selected. Furthermore, three junior and three senior out of four classes were also randomly selected from the lists of classes. Lastly, the lists of students in each selected class were compiled and systematic sampling technique was used to select every third participant on the list. Eligibility for inclusion were participants whose ages ranged between 10 and 19 years and no previous history of asthmatic related conditions. They were excluded from the study if presented with persistent cough in the last 3 months. Furthermore, individuals with presence of chest or spinal deformities such as scoliosis or kyphosis were also excluded from the study. 
The minimum sample size for this study was calculated using the formula: $n=Z^{2}(p)(1-p) / e^{2}$ where, $n=$ required sample size, $\mathrm{Z}=\mathrm{z}$-value (z-value for $95 \%$ confidence level [1.96], $\mathrm{p}=$ the estimated proportion of an attribute that is present in the population, and $\mathrm{e}=$ the desired level of precision (i.e., confidence interval, expressed as decimal [0.05] (Kasiulevičius et al., 2006). Considering the prevalence (p) of physical inactivity in Nigerian population to be $25.0 \%$ (Abubakari and Bhopal, 2008), a minimum sample size of 354 was arrived at. A total of 400 school-aged adolescents were recruited for this study to allow for 15\%-20\% attrition or missing data. However, only 385 valid data were used in the analysis yielding participants' rate of $96.3 \%$.

\section{Protocol design}

This is a cross-sectional study that involved school-aged adolescents from approved government secondary schools in Ido-Ekiti, Ekiti State, South-Western Nigeria. Ethical approval was sought and obtained from the Health Research and Ethics Committee of the Institute of Public Health, Obafemi Awolowo University IleIfe (HREC: IPH/OAU/12/495). Afterwards, approval of the Area Education Officer of Ido/Osi LGA, Ekiti-State was sought and introductory letters were taken to the various heads of selected government approved secondary schools explaining the purpose of the study. Thereafter, participants who met the inclusion criteria voluntarily gave assent to participate in the study and informed consent form was given to the participant to be delivered to their parents or guardians after the purpose for the study had been explained. A copy of validated SES questionnaire was given to each student for their parents or guardians to complete. Physical characteristics including height and weight of each participant were measured and age was recorded.

\section{Assessment of PSES}

PSES of participants was assessed using a validated SES questionnaire (Adedoyin et al., 2005). PSES indicators including education, occupation, and income were often combined in the assessment of SES level. Items also included in the questionnaire were parent's possessions of house, cars, and household assets such as television, video, refrigerator, and set of upholstery were considered as part of SES indicators. Parent's position in the community such as community leader or religious leader including pastor, imam or chief was also considered as SES indicator in Nigeria context. The scoring of the items on the questionnaire was based on their importance in Nigerian society. The summative scores of the three socio-economic indicators and respective valued properties and po- sition in the community were added together to yield a maximum obtainable score of 27 points. Actual score was divided by maximum obtainable score and then multiplied by 100 . The 25 th, 50th, and 75th percentiles were used to label transformed-scores into lower, middle and upper quartiles representing low, middle, and high levels of socioeconomic class. The instrument has good test retest reliability value $(r=0.86)$ (Adedoyin et al., 2005).

\section{Assessment of peak expiratory flow rate}

Participant's lung function (peak expiratory flow rate, PEFR) was measured at baseline using a standard peak flow meter (Microlife, PF 100, Clearwater, FL, USA). The device was re-set to zero while placing the mouthpiece in the participant's mouth between the teeth, closing the lips around it without putting the tongue inside the hole (Adedoyin et al., 2010). Participant sat uprightly on a stand chair and was instructed to take a deep breath to fill the lungs and hold the breath. Participant was then instructed to blow out as hard and fast as possible in a single blow because the first burst of the air is the most important part (Adeniyi and Erhabor, 2011). The value got was written down, but with cough or poor result, the value was discarded and process started again, the step was repeated two more times and the highest value among the three was recorded as peak flow value. The mouthpiece was cleaned with methylated spirit and cotton wool after each individual who performed the test to prevent cross infection (Adedoyin et al., 2010).

\section{Assessment of EIA}

A 6-min run test (6-MRT) was performed on a level playing ground of $50 \mathrm{~m}$ long during school break period (10:30 a.m. and 11.00 a.m.). Participants were encouraged in the standard manner by telling them to run at their own selected pace until the end of six minutes (Shimwela et al., 2014). Five min after 6-MRT, the PEFR was reassessed using the peak flow meter. Measurements of PFER was also reassessed at 5-min intervals post 6-MRT over a period of $20 \mathrm{~min}$ (i.e., 5th, 10th, 15th, and 20th $\mathrm{min}$ ) (Awopeju et al., 2011). A stopwatch (Multifunction Mini Digital Stopwatch, Whenzou Time Co. Ltd., Zhejiang, China) was used to record the duration of 6-MRT and at 5-min intervals over a period of $20 \mathrm{~min}$ post 6-MRT. Presence of EIA was determined following a $>15.0 \%$ fall in the PEFR post exercise using the formula described by (Awopeju et al., 2011; Onazi et al., 2012).

Computation: $\frac{\text { (pre exercise value }- \text { lowest of post exercise value) } \times 100}{\text { Pre exercise value }}$ 
Table 1. Physical characteristics and distribution of parental socio-economic status of participants

\begin{tabular}{|c|c|c|c|c|c|}
\hline \multirow{2}{*}{ Variable } & \multirow{2}{*}{ №. (\%) } & \multicolumn{2}{|c|}{ Mean \pm SD } & \multirow{2}{*}{$t$-cal } & \multirow{2}{*}{$P$-value } \\
\hline & & Male $(n=185)$ & Female $(n=200)$ & & \\
\hline Age (yr) & & $13.9 \pm 2.0$ & $13.8 \pm 1.6$ & 0.021 & 0.238 \\
\hline Height (m) & & $1.60 \pm 0.1$ & $1.59 \pm 0.1$ & -0.284 & 0.180 \\
\hline Weight (kg) & & $40.3 \pm 8.4$ & $39.4 \pm 3.6$ & 0.064 & 0.093 \\
\hline \multicolumn{6}{|c|}{ Socio-economic status } \\
\hline Low & 162 (42.1) & & & & \\
\hline Middle & $206(53.5)$ & & & & \\
\hline High & $17(4.4)$ & & & & \\
\hline
\end{tabular}

SD, standard deviation.

Table 2. Comparison of male and female participants' peak expiratory flow rates at baseline and post 6 -min run test at 5-min intervals $(n=385)$

\begin{tabular}{llccc}
\hline Variable & Male $(\mathrm{n}=185)$ & Female $(\mathrm{n}=200)$ & $t$-cal & $P$-value \\
\hline Baseline PEFR $(\mathrm{L} / \mathrm{m})$ & $289.4 \pm 90.3$ & $249.6 \pm 90.8$ & 1.391 & 0.165 \\
5th min PEFR $(\mathrm{L} / \mathrm{m})$ & $274.7 \pm 92.8$ & $256.3 \pm 90.7$ & 1.960 & 0.051 \\
10th $\min$ PEFR $(\mathrm{L} / \mathrm{m})$ & $291.3 \pm 93.5$ & $272.1 \pm 86.4$ & 2.090 & $0.037^{*}$ \\
15th $\min$ PEFR $(\mathrm{L} / \mathrm{m})$ & $290.7 \pm 100.5$ & $270.1 \pm 84.3$ & 2.162 & $0.031^{*}$ \\
20th $\min$ PEFR $(\mathrm{L} / \mathrm{m})$ & $301.6 \pm 86.1$ & $275.2 \pm 85.3$ & 2.978 & $0.003^{*}$ \\
\hline
\end{tabular}

Values are presented as mean \pm standard deviation.

PEFR, peak expiratory flow rate.

${ }^{*} P<0.05$.

\section{Statistical analysis}

Descriptive statistics of mean, standard deviation, frequency, and percentage was used to summarize anthropometric characteristics. Inferential statistics of independent $t$-test was used to determine the difference between male and female lung function parameter (PEFR). Chi-square test of association was used to determine association between lung function parameter (PEFR) and parental SES. Alpha level was set at $P<0.05$. The IBM SPSS Statistics ver. 19.0 (IBM Co., Armonk, NY, USA) was used to perform statistical analyses.

\section{RESULTS}

The study comprised of 200 female (51.9\%) and 185 male participants (48.1\%). The mean ages of male and female participants were $13.9 \pm 2.0$ and $13.8 \pm 1.6$ years, respectively. The distribution of PSES showed that more than half of the participants, 206 (53.5\%) belonged to the middle SES group (Table 1). Table 2 shows comparison of male and female PEFR. Baseline PEFR values for male and female were $289.4 \pm 90.3$ and $249.6 \pm 90.8 \mathrm{~L} / \mathrm{m}$, respectively. There were no significant differences between male and female PEFR at baseline $(t=1.391, P=0.165)$ and at 5 th min post 6 -MRT $(t=1.960, P=0.051)$. However, there were signifi-
Table 3. Prevalence of exercise-induced asthma among participants ( $n=385)$

\begin{tabular}{lc}
\hline Variable & No. $(\%)$ \\
\hline Induced $(>15 \%)$ & $224(58.2)$ \\
Noninduced $(<15 \%)$ & $161(41.8)$ \\
Total & $385(100)$
\end{tabular}

cant differences between male and female PEFR at 10th ( $t=$ $2.090, P=0.037), 15$ th $(t=2.126, P=0.031)$, and 20th $\mathrm{min}$ $(t=2.978 ; P=0.003)$ post 6 -MRT respectively. Table 3 showed the prevalence of EIA of the participants. The result showed that more than half of the participants, 224 (58.2\%) were found to have EIA with $>15.0 \%$ PEFR fall post 6-MRT. Chi-quare test of association showed that there was significant association between EIA and PSES $\left(\chi^{2}=152.4, P=0.001\right)$ (Table 4).

\section{DISCUSSION}

The purpose of this study was to assess the prevalence of EIA and its association with PSES among school-aged adolescents in Nigeria. Findings from our study showed that the prevalence of EIA is very high among school-aged adolescents in Nigeria. This finding is similar to the findings of previous studies in which prevalence of EIA is high among school-aged adolescents (Addo 
Table 4. Association between exercise-induced asthma, noninduced and parental socio-economic status

\begin{tabular}{|c|c|c|c|c|}
\hline \multirow{2}{*}{ Socio-economic status } & \multicolumn{2}{|c|}{ Peak expiratory flow rate score } & \multirow{2}{*}{$\chi^{2}$} & \multirow{2}{*}{$P$-value } \\
\hline & Induced (PEFR > 15.0\%) & Noninduced (PEFR $\leq 15.0 \%$ ) & & \\
\hline Low & $94(42.0)$ & $68(42.0)$ & 152.4 & $0.001^{*}$ \\
\hline Middle & $120(53.0)$ & $86(53.0)$ & & \\
\hline High & $10(5.0)$ & $7(5.0)$ & & \\
\hline
\end{tabular}

Values are presented as number (\%).

PEFR, peak expiratory flow rate.

${ }^{*} P<0.05$.

Yobo et al., 1997; Ng'ang'a et al., 1998). Kenya studies reported prevalence rates of $21.0 \%$ and $23.0 \%$ among school-aged adolescents in a pilot and main studies respectively while South Africa reported a prevalence rate of $23.0 \%$ among school-aged adolescents (Ng'ang'a et al., 1998). The plausible explanation for the high prevalence of EIA may be attributed to poor neighbourhood environment where the studies were conducted. Majority of roads of African cities are dusty and full of different allergies that may trigger asthmatic symptoms. It is also possible that the use of biomass materials for cooking food at homes which is still a regular practice in Africa could play a significant role thus precipitating the development of COPD including asthma. Furthermore, presence of poor air quality as a result of exhaust fumes due to an increased number of automobiles in major towns and cities may be part of contributing factors for high prevalence of undetected and undiagnosed respiratory conditions including EIA. However, contrary to the findings of this study, studies from other parts of Africa reported low prevalence of EIA. For instance, studies from Morocco and Zimbabwe reported prevalence rates of $9.5 \%$ and $5.8 \%$, respectively (Keeley et al., 1991; Terblanche and Stewart, 1990). In another study from South Africa, prevalence rates of $5.8 \%$ and $4.1 \%$ were reported among white children living in urban centres and coloured school-aged adolescents in rural South Africa respectively (Mtshali and Mokwena, 2009). The reason for the disparity in African regions may be attributed to the differences in weather condition, home setting including overcrowding, low birth weight and environmental factors.

The prevalence of EIA in this study is higher than a previous study in northern Nigeria and other African countries including Ghana, South Africa and Zimbabwe (Addo Yobo et al., 1997; Keeley et al., 1991; Mtshali and Mokwena, 2009; Onazi et al., 2012). The reasons for the differences may be due to diverse lifestyles including parental smoking habit, poor dietary habit, physical inactivity, obesity, outdoor pollutants and family history of asthmatic symptoms and allergy (Asani et al., 2005; Moshammer et al., 2006). Furthermore, the methodological approaches used in the assessment of EIA may also contribute to these disparities across Africa. Different authors used varieties of cutoff points to determine the PEFR fall. For instance, Ng'ang'a et al. (1998) in Kenya used $>10.0 \%$, Addo Yobo et al. (1997) from Ghana used $>12.5 \%$ and $>15.0 \%$ while Shimwela et al. (2014) used $\geq 20.0 \%$ among school-aged adolescents in Tanzania. We used $>15.0 \%$ PEFR which is considered to be the standard criteria (Awopeju et al., 2011; Onazi et al., 2012). The duration of intervals of recording PEFR value in response to exercise test was also different. The usual duration after exercise for measuring the PEFR was from 5th to 20th min at 5-min intervals and the number of trials done to complete single measurement. Others include difference in population selections in terms of age and sex distributions.

Findings from our study show that school-aged adolescents belonged to different parental socio-economic strata. More than half of the participants' parents were found to in the middle socioeconomic class. Interestingly, findings from our study showed that there was a significant association between EIA and PSES. This is in agreement with the findings of previous studies that reported significant association between EIA and SES across different groups (Poyser et al., 2002; Sporik et al., 1999). On the contrary, reports from developed nations including Great Britain, Italy, Sweden, Sydney, and USA showed that there was no significant association between EIA and SES (Peat et al., 1980; Persky et al., 1998; Strachan et al., 1994). However, some of these studies focused on the association between other respiratory allergies and SES. It is possible that SES plays little or no role in the prevalence of EIA in some of these developed nations. Firstly, presence of medical facilities in terms of early diagnosis of EIA may reduce its prevalence and secondly, provision of good nutritional care from childhood may also serve as protective mechanism against EIA. Furthermore, the SES of developed nations is not likely to be comparable with that of developing nations including Africa due to high per capita income which is an important determinant of health (Lobmayer and Wilkinson, 2000; Lynch et al., 1997). Although SES is a complex construct which may be difficult to mea- 
sure in different societies or regions, our study employed standard and known SES indicators such as monthly income, educational level and occupation of the parents or guardian including valuable possessions in the assessment of SES.

Reports of some studies from Britain, Singapore, Hong Kong, and South China showed that prevalence of EIA was high among adolescents of middle or high socio-economic class (Peat et al., 1980; Persky et al., 1998; Poyser et al., 2002). Previously, Mielck et al. (1996) in a population-based study reported that asthma prevalence rates are higher among individuals of high SES based on hygiene hypothesis. It is believed that living in areas with high standards of sanitation with clean houses and environment, frequent access to antibiotics, vaccination and reduced exposure to viral, bacteria and helminthic infections may increase the risk of allergic diseases including asthma (Lynch et al., 1997; Weinberg, 2000). On the other hand, Kalliomaki and Isolauri (2002) suggested that high burdens of viruses and intracellular bacteria as it applied to children with low SES, which frequently cause childhood infections in developing countries may deviate the early childhood Th2-type cytokines (Th2-biased), atopy-prone immune system to a Th1-type cytokines immune system which may protect against the development of allergies. Though presence of infection which may induce strong Th2-type responses with production of interleukin (IL); IL-4, IL-5, and IL-13 and consequently increase the $\operatorname{IgE}$ synthesis, helps to provide protection against allergy among active individual (Bloomfield et al., 2012; Mao et al., 2000).

It is now evident that early detection of EIA may be treated to prevent full-blown asthma through prescribed medications and self-managed care such as personal hygienic practices and regular physical activity participation (Chandratilleke et al., 2012). The risk of EIA attacks tends to be low among individuals who are aware of the problem, remain physically active and prepared for the physical exertion (Williams et al., 2008). Physical exercise has been reported to enhance endurance capacity, increase airway clearance and effective lung tissue elastic recoil, and improve immunity against allergies (Stickland et al., 2012; Walsh et al., 2011). Furthermore, aerobic exercise has been reported to reduce airway remodelling, with reduced airway smooth muscle hypertrophy and hyperplasia, a reduction in leukocyte infiltration, pro-inflammatory cytokine production, adhesion molecules expression, and enhanced regulatory T-cell responses (Pastva et al., 2004; Vieira et al., 2011). However, there is general consensus among exercise experts on the type and intensity of exercise that may be beneficial for individuals with asthmatic condition. Most experts favor regular moderate intensity aerobic exercise programmes as vigorous high intensity may trigger EIA (Ries et al., 2007; Vieira et al., 2011). Findings from our study should be interpreted with caution due to some inherent limitations. The study design is a cross-sectional one and may limit its generalizability to other adolescents in different settings. Furthermore, previous history of respiratory conditions in the study population could not be confirmed through medical examination, hence, it may affect the outcome of this study. In conclusion, prevalence of EIA is very high among school-aged adolescents in Nigeria and is significantly associated with PSES. Efforts should be made to increase public awareness about EIA and develop a strategy to reduce future risk of asthmatic and allergic conditions.

\section{CONFLICT OF INTEREST}

No potential conflict of interest relevant to this article was reported.

\section{ACKNOWLEDGMENTS}

The authors wish to thank the Consortium for Advanced Research Training in Africa (CARTA) for providing technical support. CARTA is jointly led by the African Population and Health Research Centre and the University of the Witwatersrand and funded by the Wellcome Trust (UK) (grant number: 087547/ Z/08/Z), the Department for International Development (DfID) under the Development Partnerships in Higher Education (DelPHE), the Carnegie Corporation of New York (grant number: B 8606), the Ford Foundation (grant number: 1100-0399), Swedish International Development Corporation Agency - SIDA (grant number: 54100029), Google.Org.

\section{REFERENCES}

Abubakari AR, Bhopal RS. Systematic review on the prevalence of diabetes, overweight/obesity and physical inactivity in Ghanaians and Nigerians. Public Health 2008;122:173-182.

Addo Yobo EO, Custovic A, Taggart SC, Asafo-Agyei AP, Woodcock A. Exercise induced bronchospasm in Ghana: differences in prevalence between urban and rural schoolchildren. Thorax 1997;52:161-165.

Adedoyin RA, Erhabor GE, Olajide A, Anifowose OJ. Influence of self-reported socio-economic status on lung function of adult Nigerians. Physiotherapy 2010;96:191-197.

Adedoyin RA, Mbada CE, Awofolu OO, Oyebami OM. The influence of 
socio-economic status on casual blood pressures of the adult Nigerians. Eur J Cardiovasc Prev Rehabil 2005;12:271-273.

Adeloye D, Chan KY, Rudan I, Campbell H. An estimate of asthma prevalence in Africa: a systematic analysis. Croat Med J 2013;54:519-531.

Adeniyi BO, Erhabor GE. The peak flow meter and its use in clinical practice. Afr J Respir Med 2011;7:5-8.

Akanbi MO, Ukoli CO, Erhabor GE, Akanbi FO, Gordon SB. The burden of respiratory disease in Nigeria. Afr J Respir Med 2009;5:10-17.

Anderson SD, Holzer K. Exercise-induced asthma: is it the right diagnosis in elite athletes? J Allergy Clin Immunol 2000;106:419-428.

Asani MO, Adeleke SI, Ibrahim M. Childhood asthma in Kano, Nigeria. Niger J Basic Clin Sci 2005;2:6-9.

Awopeju OF, Erhabor GE, Balogun MO, Obaseki DO, Erhabor FA, Adewole OO. Exercise-induced asthma in adult Nigerian asthma patients: a comparison of step test, free running, and bicycle ergometer. Afri J Respir Med 2011;7: 8-10.

Awotidebe TO, Adeyeye VO, Ativie RN, Adedoyin RA, Borode AO, Balogun $\mathrm{MO}$, Akindele MA. Functional capacity and psychosocial correlates of exercise in Nigerian patients with hypertension. Int J Clin Med 2016;7:464-473.

Bloomfield SF, Stanwell-Smith R, Rook GA. The hygiene hypothesis and its implications for home hygiene, lifestyle and public health: summary [Internet]. International Scientific Forum on Home Hygiene; 2012 [cited 2016 Apr 18]. Available from: https://www.ifh-homehygiene. org/best-practice-review/hygiene-hypothesis-and-its-implicationshome-hygiene-lifestyle-and-public.

Chandratilleke MG, Carson KV, Picot J, Brinn MP, Esterman AJ, Smith BJ. Physical training for asthma. Cochrane Database Syst Rev 2012;16;(5): CD001116.

Crain EF, Weiss KB, Bijur PE, Hersh M, Westbrook L, Stein RE. An estimate of the prevalence of asthma and wheezing among inner-city children. Pediatrics 1994;94:356-362.

Cukic V, Lovre V, Dragisic D, Ustamujic A. Asthma and chronic obstructive pulmonary disease (COPD) - differences and similarities. Mater Sociomed 2012;24:100-105.

Erhabor GE, Agbroko SO, Bamigboye P, Awopeju OF. Prevalence of asthma symptoms among university students 15 to 35 years of age in Obafemi Awolowo University, Ile-Ife, Osun State. J Asthma 2006;43: 161-164.

Government of Ekiti State, Nigeria. Ekiti State in the news, 2015 [Internet]. Ekiti State (Nigeria): Government of Ekiti State, Nigeria; c2017 [cited 2016 Oct 14]. Available from: www.ekitistate.gov.ng/category/news/.

Janson C, Anto J, Burney P, Chinn S, de Marco R, Heinrich J, Jarvis D, Kuenzli N, Leynaert B, Luczynska C, Neukirch F, Svanes C, Sunyer J, Wjst M; European Community Respiratory Health Survey II. The Eu- ropean Community Respiratory Health Survey: what are the main results so far? European Community Respiratory Health Survey II. Eur Respir J 2001;18:598-611.

Kalliomäki M, Isolauri E. Pandemic of atopic diseases: a lack of microbial exposure in early infancy? Curr Drug Targets Infect Disord 2002;2:193199.

Kasiulevičius V, Šapoka V, Filipavičiūtè R. Sample size calculation in epidemiological studies. Gerontologija 2006;7:225-231.

Keeley DJ, Neill P, Gallivan S. Comparison of the prevalence of reversible airways obstruction in rural and urban Zimbabwean children. Thorax 1991;46:549-553.

Lan CC, Yang MC, Lee CH, Huang YC, Huang CY, Huang KL, Wu YK. Pulmonary rehabilitation improves exercise capacity and quality of life in underweight patients with chronic obstructive pulmonary disease. Respirology 2011;16:276-283.

Lobmayer P, Wilkinson R. Income, inequality and mortality in 14 developed countries. Sociol Health Illn 2000;22:401-404.

Lynch NR, Palenque M, Hagel I, DiPrisco MC. Clinical improvement of asthma after anthelminthic treatment in a tropical situation. Am J Respir Crit Care Med 1997;156:50-54

Mao XQ, Sun DJ, Miyoshi A, Feng Z, Handzel ZT, Hopkin JM, Shirakawa T. The link between helminthic infection and atopy. Parasitol Today 2000;16:186-188.

Matsui EC. Environmental exposures and asthma morbidity in children living in urban neighborhoods. Allergy 2014;69:553-558.

Mielck A, Reitmeir P, Wjst M. Severity of childhood asthma by socioeconomic status. Int J Epidemiol 1996 252:388-393.

Mohammed J, Adedoyin RA, Awotidebe TO, Onigbinde AT. Influence of parental socioeconomic status on lung function indices of children in Ile Ife, Nigeria. J Niger Soc Physiother 2012;20:67-71.

Moshammer H, Hoek G, Luttmann-Gibson H, Neuberger MA, Antova T, Gehring U, Hruba F, Pattenden S, Rudnai P, Slachtova H, Zlotkowska $\mathrm{R}$, Fletcher T. Parental smoking and lung function in children: an international study. Am J Respir Crit Care Med 2006;173:1255-1263.

Mtshali BF, Mokwena KE. The prevalence of exercise-induced asthma among school children. SA Fam Pract 2009;51:489-491.

Ng'ang'a LW, Odhiambo JA, Mungai MW, Gicheha CM, Nderitu P, Maingi B, Macklem PT, Becklake MR. Prevalence of exercise induced bronchospasm in Kenyan school children: an urban-rural comparison. Thorax 1998;53:919-926.

Okada H, Kuhn C, Feillet H, Bach JF. The 'hygiene hypothesis' for autoimmune and allergic diseases: an update. Clin Exp Immunol 2010;160:1-9.

Onazi SO, Orogade AA, Yakubu AM. Exercise-induced bronchospasm among school children in Gusau, Nigeria. West Afr J Med 2012;31:7680 . 
Pastva A, Estell K, Schoeb TR, Atkinson TP, Schwiebert LM. Aerobic exercise attenuates airway inflammatory responses in a mouse model of atopic asthma. J Immunol 2004;172:4520-4526.

Peat JK, Woolcock AJ, Leeder SR, Blackburn CR. Asthma and bronchitis in Sydney schoolchildren. II. The effect of social factors and smoking on prevalence. Am J Epidemiol 1980;111:728-735.

Persky VW, Slezak J, Contreras A, Becker L, Hernandez E, Ramakrishnan V, Piorkowski J. Relationships of race and socioeconomic status with prevalence, severity, and symptoms of asthma in Chicago school children. Ann Allergy Asthma Immunol 1998;81:266-271.

Poyser MA, Nelson H, Ehrlich RI, Bateman ED, Parnell S, Puterman A, Weinberg E. Socioeconomic deprivation and asthma prevalence and severity in young adolescents. Eur Respir J 2002;19:892-898.

Ries AL, Bauldoff GS, Carlin BW, Casaburi R, Emery CF, Mahler DA, Make B, Rochester CL, Zuwallack R, Herrerias C. Pulmonary Rehabilitation: Joint ACCP/AACVPR Evidence-Based Clinical Practice Guidelines. Chest 2007;131(5 Suppl):4S-42S.

Shimwela M, Mwita JC, Mwandri M, Rwegerera GM, Mashalla Y, Mugusi F. Asthma prevalence, knowledge, and perceptions among secondary school pupils in rural and urban coastal districts in Tanzania. BMC Public Health 2014;14:387.

Sporik R, Squillace SP, Ingram JM, Rakes G, Honsinger RW, Platts-Mills TA. Mite, cat, and cockroach exposure, allergen sensitisation, and asthma in children: a case-control study of three schools. Thorax 1999; 54:675-680.

Stickland MK, Rowe BH, Spooner CH, Vandermeer B, Dryden DM. Effect of warm-up exercise on exercise-induced bronchoconstriction. Med Sci Sports Exerc 2012;44:383-391.

Strachan DP, Anderson HR, Limb ES, O'Neill A, Wells N. A national survey of asthma prevalence, severity, and treatment in Great Britain.

\section{Arch Dis Child 1994;70:174-178}

Terblanche E, Stewart RI. The prevalence of exercise-induced bronchoconstriction in Cape Town schoolchildren. S Afr Med J 1990;78:744-747.

The International Study of Asthma and Allergies in Childhood (ISAAC) Steering Committee. Worldwide variation in prevalence of symptoms of asthma, allergic rhinoconjunctivitis, and atopic eczema: ISAAC. Lancet 1998;351:1225-1232.

United States Department of Health and Human Services (USDHHS). Physical Activity Guidelines Advisory Committee. Physical Activity Guidelines Reports, 2008 Washington, DC: Department of Health and Human Services; 2008.

Vieira RP, Toledo AC, Ferreira SC, Santos AB, Medeiros MC, Hage M, Mauad T, Martins Mde A, Dolhnikoff M, Carvalho CR. Airway epithelium mediates the anti-inflammatory effects of exercise on asthma. Respir Physiol Neurobiol 2011;175:383-389.

Walsh NP, Gleeson M, Shephard RJ, Gleeson M, Woods JA, Bishop NC, Fleshner M, Green C, Pedersen BK, Hoffman-Goetz L, Rogers CJ, Northoff H, Abbasi A, Simon P. Position statement. Part one: Immune function and exercise. Exerc Immunol Rev 2011;17:6-63.

Weinberg EG. Urbanization and childhood asthma: an African perspective. J Allergy Clin Immunol 2000;105(2 Pt 1):224-231.

Williams B, Powell A, Hoskins G, Neville R. Exploring and explaining low participation in physical activity among children and young people with asthma: a review. BMC Fam Pract 2008;9:40.

World Health Organization. World Health Organization Report. Global recommendations for physical activity for health [Internet]. Geneva (Switzerland): World Health Organization; 2010 [cited 2015 Aug 10]. Available from: http://apps.who.int/iris/bitstream/10665/44399/1/978 9241599979_eng.pdf. 